\title{
In Vitro Establishment and Multiplication of the Normania triphylla (Lowe) Lowe
}

\author{
David Delmail $^{1,2,3^{*}}$, Pascal Labrousse ${ }^{2}$, Jean-Yves Lesouëf ${ }^{3}$, François Le Hir $^{3}$, Jean-Luc \\ Autret $^{3}$ and Michel Botineau ${ }^{2}$ \\ ${ }^{1}$ Laboratory of Pharmacognosy and Mycology; University of Rennes1; UMR CNRS 6226 SCR/PNSCM, 2; Av. Du \\ Prof. Léon Bernard, 35043; Rennes - France. ${ }^{2}$ Laboratory of Botany; University of Limoges, 2; Rue Du Dr. \\ Marcland, 87025; Limoges - France. ${ }^{3}$ National Botanical Conservatory of Brest, 52; Allée Du Bot, 29200; Brest - \\ France
}

\begin{abstract}
Normania triphylla is an endemic species from Madeira island (Portugal) extinct in the wild since 1991. The aim of this work was to culture the meristems of this species in vitro and to multiply its shoots in order to preserve this endangered species. The best results in terms of multiplication were obtained in Murashige and Skoog medium supplemented with $10 \mu \mathrm{M}$ 6-benzylaminopurine (BAP). The number of shoots, the number of nodes and the number of leaves were the most important in this medium. However, the best results concerning the total shoot length were obtained when BAP was not supplemented into the medium and in the presence of 5 or $7.5 \mu M$ 1-naphtalene acetic acid (NAA). This is the first report on the in vitro culture of $\mathrm{N}$. triphylla which could brings new avenues for the development of this species.
\end{abstract}

Key words: Normania, Endemic species, Micropropagation, 6-benzylaminopurine, Callus

\section{INTRODUCTION}

The Normania genus belonging to the Solanaceae family is endemic to the Macaronesian archipelago. Normania triphylla (Lowe) Lowe is restricted to the Madeira island (Portugal) and Normania nava (Webb et Berthel.) Franc.-Ort. et R. N. Lester is found in Tenerife and Gran Canaria (Spain) (Bohs and Olmstead 2001; Francisco-Ortega et al. 1993). N. triphylla is extinct in the wild since 1991 but it is naturalized in the National Botanical Conservatory of Brest (France). N. nava is presumed as definitely extinct because no specimen has been observed for more than 25 years. These two very rare species could probably constitute only one species with two subspecies or varieties (Francisco-Ortega et al.
1993). Recently, these two taxa were reassessed as Solanum nava Webb et Berthel. and Solanum trisectum Dunal (Bohs and Olmstead 2001).

In situ preservation of Normania could only be achieved through the conservation of the primary laurel forest, its natural habitat. The only efficient way to preserve these species and to allow further reintroduction appears to be ex situ conservation. But, even in the botanical conservatory, $N$. triphylla could be attacked by several pathogens such as Oidium neolycopersici (Delmail and Autret 2010) and its development and/or its conservation could be problematic. To achieve this goal of biodiversity preservation, in vitro culture and micropropagation of $N$. triphylla appears as a promising technique as it has been used previously with success for some other endangered species

\footnotetext{
*Author for correspondence: david.delmail@wanadoo.fr
} 
such as Symonanthus bancroftii, a Western Australian solanaceous shrub (Panaia et al. 2000), devil's claw, Harpagophytum procumbens, a medicinal plant from Africa (Kaliamoorthy et al., 2008) or Plantago algarbiensis and $P$. almogravensis, two endemic aluminium-tolerant species from Portugal (Gonçalves et al. 2009). The in vitro preservation of endangered plants has been reviewed by Sarasan et al. (2006), and Gonzales-Benito and Martin (2011).

Thus, the aim of this study was to establish in vitro culture of $N$. triphylla and to define the optimal culture conditions in order to obtain the micropropagation of this extinct in the wild plant species. The ultimate goal was the mass production of $N$. triphylla to allow the studies on this extremely rare species and even if appropriate reintroduction in the natural habitat to promote in situ conservation.

\section{MATERIAL AND METHODS}

A $N$. triphylla seedling was kindly provided by J.Y. Lesouëf, curator of the National Botanical Conservatory of Brest until 2006. Ten lateral buds of the plant were sampled in order to establish the in vitro culture.

After one surface disinfection in $70^{\circ}$ ethanol during $10 \mathrm{~s}$ and in $0.951 \%$ active-chlorine $\mathrm{NaOCl}$ during $3 \mathrm{mn}, 51$ meristems were isolated and placed on modified MS medium (Murashige and Skoog 1962) according to Desilets et al. (1993) (macroelements $/ 2+$ microelements + vitamins) at pH 5.8 according to Delmail et al. $(2011 \mathrm{~b}, \mathrm{c})$ complemented with $0.11 \mu \mathrm{M}$ 1-naphthalene acetic acid (NAA), $0.89 \mu \mathrm{M}$ 6-benzylaminopurine (BAP), 30 g.dm ${ }^{-3}$ sucrose and 5 g.dm ${ }^{-3}$ agar (HP 696, Kalys). After five weeks of culture, developed shoots in the test tubes were trimmed in one node explants and ten explants were subcultured on MS medium in polypropylene Sterivent boxes $(80 \times 110 \times 100 \mathrm{~mm}$, Kalys) (36 boxes, 10 explants per box).

In order to assess the effects of twelve combinations of BAP/NAA concentrations $(0 / 0$, 0/5, 0/7.5, 5/0, 5/5, 5/7.5, 7.5/0, 7.5/5, 7.5/7.5, $10 / 0,10 / 5,10 / 7.5 \mu \mathrm{M}$ BAP/NAA), on $N$. triphylla multiplication, 30 nodal explants per condition were assessed in term of survival, number of shoot, number of leaves, number of nodes and average total shoot length.
The cultures were maintained during 35 days in a growth cabinet set at $24 \pm 2^{\circ} \mathrm{C}$, with a photoperiod of $16 \mathrm{~h} / 24 \mathrm{~h}$ and a light intensity of $13.83 \pm 5.83$ $\mu \mathrm{mol} . \mathrm{m}^{-2} \cdot \mathrm{s}^{-1}$ (neon Supra'Lux Actizoo, 30W).

After normality analysis with Shapiro-Francia test (Delmail et al., 2011a), the data were subjected to the analysis of variance (ANOVA) with the general linear model procedure $(R$ statistical package for Windows, release 2.11.0; the $R$ Foundation, Vienna, Austria) to assess the treatment differences. Significant differences between the means were determined by Duncan's new multiple range test at a significance level of 5\%.

\section{RESULTS AND DISCUSSION}

Sixty percent of the cultured meristems presented a callogenesis and a further shoot development leading to a successful establishment of the $N$. triphylla in vitro culture. Whatever the considered parameters (number of shoots, number of nodes or number of leaves), the best medium for $N$. triphylla micropropagation was the MS medium, supplemented with $10 \mu \mathrm{M}$ BAP and devoid of NAA (Fig. 1). An increase in these parameters clearly appeared with the increasing concentration of BAP in the medium when NAA was discarded $(P<0.05)$. For the last parameter, the total shoot length, an increase was noted until $7.5 \mu \mathrm{M}$ BAP but a decrease appeared at $10 \mu \mathrm{M}$.

When NAA was added at 5 or $7.5 \mu \mathrm{M}$, no significant effect on the leaf, shoot and node numbers could be noted whatever was the BAP concentration $(P<0.05)$. In all these cases, the number of shoots, leaves and nodes decreased compared with the $10 \mu \mathrm{M} \mathrm{BAP} / 0 \mu \mathrm{M}$ NAA treatment. Concerning the total shoot length, the best results were obtained when the medium was devoid of BAP and in the presence of 5 or $7.5 \mu \mathrm{M}$ NAA $(P<0.05)$.

It should be noted that callogenesis was frequently observed at the base of the explants in all the tested culture media (Fig. 2). Only few spontaneous rooting were observed and only the roots produced on the callus were observed. Moreover, sporadic flowering could be observed during the multiplication phase. These results, indicating a good multiplication rate for the $10 \mu \mathrm{M}$ $\mathrm{BAP} / 0 \mu \mathrm{M}$ NAA supplemented medium (and in a lesser extent for the $7.5 \mu \mathrm{M}$ BAP/0 $\mu \mathrm{M}$ NAA supplemented medium), were not in agreement with the results of Boufleuher et al. (2008) 
presenting an inhibitory effect of NAA and BAP on shoot-bud growth and differentiation in Solanum sessiliflorum. Contrarily, Arockiasamy et al. (2002) noted a high multiple shoot induction from the nodal explant in Solanum trilobatum with a combination of $5 \mathrm{mg} . \mathrm{dm}^{-3}$ BAP and $0.05 \mathrm{mg} \cdot \mathrm{dm}^{-}$ ${ }^{3}$ NAA $(22.2 \mu \mathrm{M}$ BAP/0.27 $\mu \mathrm{M}$ NAA), a result much more in agreement with the present results for N. triphylla.

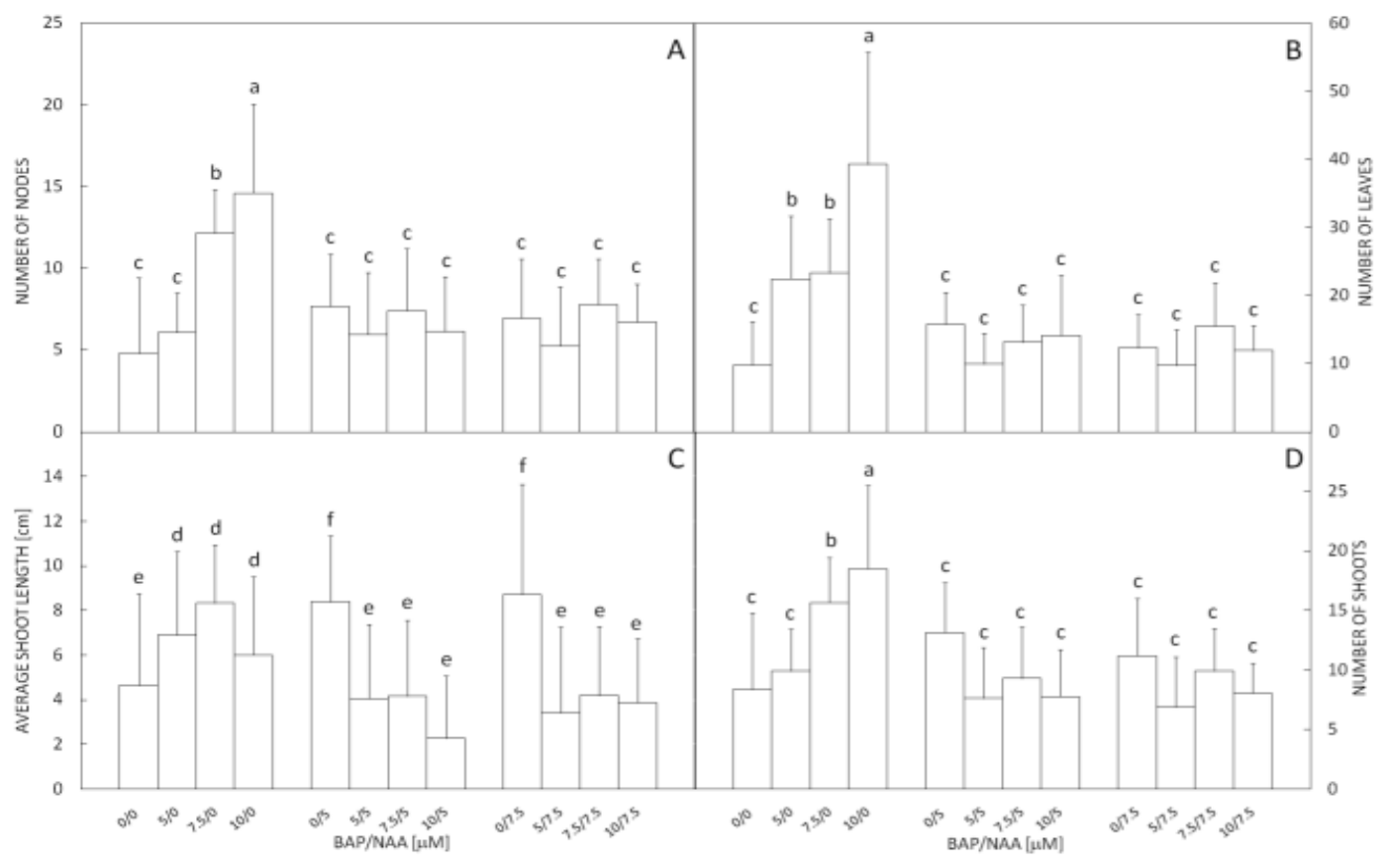

Figure 1 - Effects of BAP/NAA combinations in the culture medium on the morphological parameters of Normania triphylla. A - effects on the number of nodes per explant; $B$ effects on the number of leaves per explant; $C$ - effects on the average total shoot length; $D$ - effects on the number of shoots per explant. Histograms with above the same letter are not significantly different (5\% level - Duncan's test).
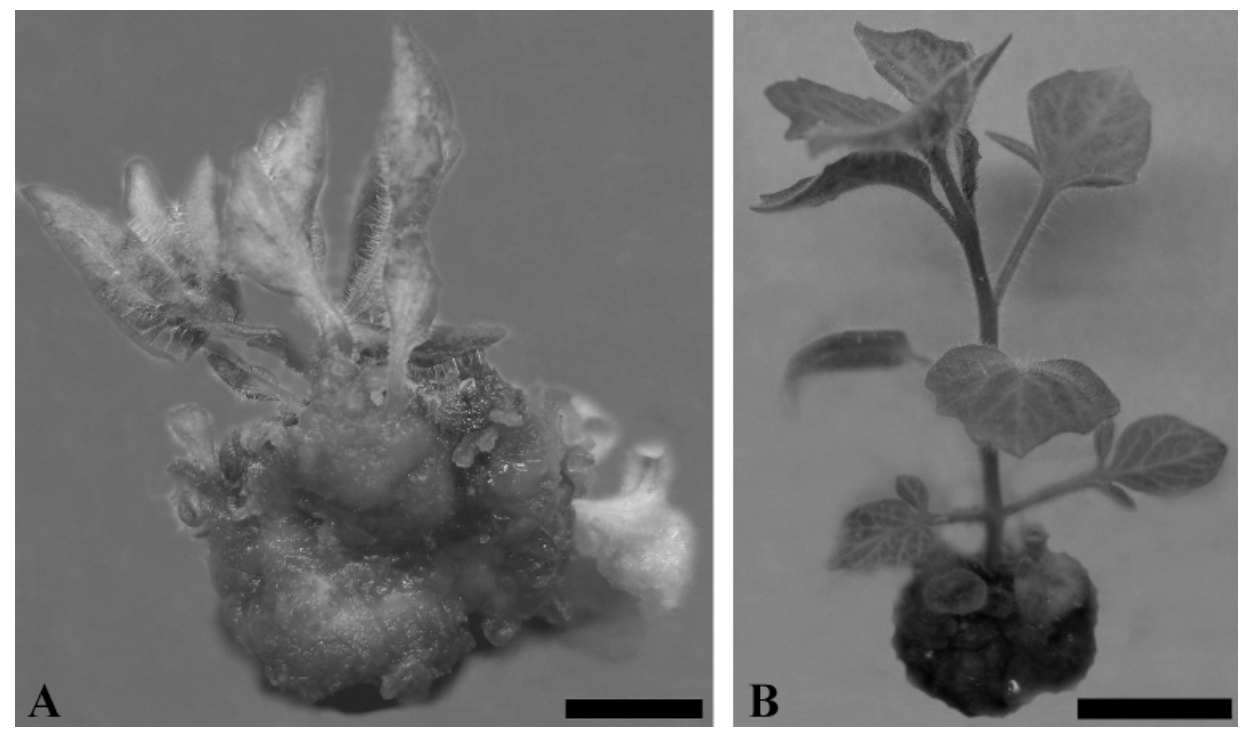

Figure 2 - Normania triphylla explant after 5 weeks of culture exposed at $10 \mu \mathrm{M}$ BAP/5 $\mu \mathrm{M}$ NAA $(A, b a r=1 \mathrm{~cm})$ and at $10 \mu \mathrm{M}$ BAP/7.5 $\mu \mathrm{M}$ NAA $(B, b a r=2 \mathrm{~cm})$. 
It would be interesting to test the effects of thiadiazuron (TDZ) and of indole-3-acetic acid (IBA) on shoot bud induction and root formation of $N$. triphylla, respectively, as in the case of Solanum surratense positive effects were observed during in vitro regeneration in the presence of 0.1 mg.dm ${ }^{-3}$ TDZ and $1 \mathrm{mg} \cdot \mathrm{dm}^{-3}$ IBA (Yadav et al., 2010). Efficient rooting was also observed in another Solanaceae, Cyphomandra betacea, with $1.5 \mathrm{mg} \cdot \mathrm{dm}^{-3}$ IBA (Chakraborty and Roy 2006). Moreover, kinetin could be also tested on $N$. triphylla shoot propagation as $1 \mathrm{mg} \cdot \mathrm{dm}^{-3}$ of this cytokinin in the culture medium increased the shoot number of Withania somnifera (Sabir et al. 2008).

As previously developed for other species (Labrousse et al. 2012), in vitro rooting and acclimation assays are currently in progress to establish a complete in vitro to ex vitro regeneration protocol for this species. It should be noted that, as in the case of Swertia chirayita described by Joshi and Dhawan (2007), it would be useful to assess the genetic fidelity of micropropagated plants to limit the impact of somaclonal variation on this endangered species. It is the first report of $N$. triphylla in vitro culture establishment and micropropagation. Even if rooting tests and acclimation must be done for further greenhouse or in situ conservation, this study constitutes an important breakthrough in the preservation of this extremely endangered species.

\section{ACKNOWLEDGMENTS}

This work was supported by the National Botanical Conservatory of Brest and the Conseil Régional du Limousin.

\section{REFERENCES}

Arockiasamy DI, Muthukumar B, Natarajan E, Britto SJ. Plant regeneration from node and internode explants of Solanum trilobatum L. Plant Tissue Cult Biotech. 2002; 12(2): 93-7.

Bohs L, Olmstead RG. A reassessement of Normania and Triguera (Solanaceae). Plant Syst Evol. 2001; 228(1-2): 33-48.
Boufleuher LM, Schuelter AR, Luz CL, da Luz CL, Antes VA, Stefanello S, Comerlato AP, Otoni WC. In vitro propagation of Solanum sessiliflorum as affected by auxin and cytokinin combinations and concentrations. Asian J Plant Sci. 2008; 7(7): 639646.

Chakraborty S, Roy SC. Micropropagation of Cyphomandra betacea (CAV.) sendt., a potential horticultural and medicinal plant, by axillary bud multiplication. Phytomorphology. 2006; 56(1-2): 2933.

Delmail D, Autret JL. First description of Oidium neolycopersici (Erysiphaceae) in France, on a new host plant extinct in the wild. Mycotaxon. 2010; 113(1): 269-271.

Delmail D, Labrousse P, Botineau M. The most powerful multivariate normality test for plant genomics and dynamics data sets. Ecol Inform. 2011a; 6(2): 125-6.

Delmail D, Labrousse P, Hourdin P, Larcher L, Moesch C, Botineau M. Differential responses of Myriophyllum alterniflorum DC (Haloragaceae) organs to copper: physiological and developmental approaches. Hydrobiologia. 2011b; 664(1): 95-105.

Delmail D, Labrousse P, Hourdin P, Larcher L, Moesch C, Botineau M. Physiological, anatomical and phenotypical effects of a cadmium stress in differentaged chlorophyllian organs of Myriophyllum alterniflorum DC (Haloragaceae). Environ Exp Bot. 2011c; 72(2): 174-181.

Desilets H, Desjardins Y, Belanger RR. Clonal propagation of Pelargonium $x$ hortorum through tissue culture: effect of salt dilution and growth regulator concentration. Can J Plant Sci. 1993; 73(1): 871-8.

Francisco-Ortega J, Hawkes JG, Lester RN, AcebesGinoves JR. Normania, an endemic Macaronesian genus distinct from Solanum (Solanaceae). Plant Syst Evol. 1993; 185(3-4): 189-205.

Gonçalvez S, Martins N, Romano A. Micropropagation and conservation of endangered species Plantago algarbiensis and P. almogravensis. Biol Plantarum. 2009; 53(4): 774-8.

Gonzales-Benito ME, Martin C. In vitro preservation of Spanish biodiversity. In vitro Cell Dev-Pl. 2011; 47(1): 46-54.

Joshi P, Dhawan V. Assessment of genetic fidelity of micropropagated Swertia chirayita plantlets by ISSR marker assay. Biol Plantarum. 2007; 51(1): 22-6.

Kaliamoorthy S, Naidoo G, Achar P. Micropropagation of Harpagophytum procumbens. Biol Plantarum. 2008; 52(1): 191-4. 
Labrousse P, Delmail D, Arnaud MC, Thalouarn P. Mineral nutrient concentration influences sunflower infection by broomrape (Orobanche cumana). Botany. 2010; 88(9): 839-849.

Labrousse P, Delmail D, Decou R, Carlué M, Lhernould S, Krausz P. Nemesia root hair response to paper pulp substrate for micropropagation. TheScientific WorldJournal. 2012; 859243: 1-7.

Murashige T, Skoog F. A revised medium for rapid growth and bioassays with tobacco tissue cultures. Physiol Plantarum. 1962; 15(3): 472-497.

Panaia M, Senaratna T, Bunn E, Dixon KW, Sivacithamparam K. Micropropagation of the critically endangered Western Australian species Symonanthus bancroftii (F. Muell.) L. Haegi (Solanaceae). Plant Cell Tiss Org. 2000; 63(1): 23-9.

Sabir F, Sangwan NS, Chaurasiya ND, Misra LN, Tuli R, Sangwan RS. Rapid micropropagation of Withania somnifera L. accessions from axillary meristems. $J$ Herb Spices Med Plant. 2008; 13(4): 123-133.
Sarasan V, Cripps R, Ramsay MM, Atherton C, McMichen M, Prendergast G, et al. Conservation in vitro of threatened plants - progress in the past decade. In Vitro Cell Dev-Pl. 2006; 42(3): 206-214.

Yadav SK, Kachhwaha S, Kothari SL. Comparison of in vitro regeneration efficiency of leaf explants in response to different cytokinins and assessment of genetic uniformity of regenerated plants of Solanum surattense Burm.f. Afr J Biotech. 2010; 9(53): 89917.

Received: May 09, 2011; Revised: August 02, 2011; Accepted: February 14, 2012. 


\section{PAGINA EM}

B RANCO 